\title{
Calibration of a Hybrid Heat Pump System and Application of an Energy Manager in Building Performance Simulations
}

\author{
Philipp Mehrfeld ${ }^{1}$, Martin Steinbach ${ }^{1}$, Markus Nürenberg ${ }^{1}$, Moritz Lauster ${ }^{1}$, Dirk Müller ${ }^{1}$ \\ ${ }^{1}$ RWTH Aachen University, E.ON Energy Research Center, Institute for Energy Efficient \\ Buildings and Indoor Climate, Aachen, Germany \\ Corresponding Author: pmehrfeld@eonerc.rwth-aachen.de
}

\begin{abstract}
In order to receive reliable results from a coupled building performance and HVAC simulation, the usage of calibrated models is advantageous. In this case study, monitoring data from a hardware-in-the-loop experiment is the basis for the calibration of an energy conversion system consisting of an air source heat pump, a condensing gas boiler (CGB), a thermal energy storage as well as the system controller. Since technical systems normally need expert knowledge to be calibrated adequately, this paper presents clear overviews about input and target values as well as tunable parameters for each subsystem. With satisfying results in terms of RMSE, three scenarios including a one family house are simulated. These scenarios differ in usage of heat pump, CGB and photovoltaic cells. In the end, results reveal that a fictive system existing of only the CGB lead to the lowest operational costs. This is mostly due to actual COPs that are worse than by the system controller predicted ones.
\end{abstract}

\section{Introduction}

In the building energy sector, electrically driven heat pumps (HP) must be considered as an upcoming key technology in order to make use of the electricity generated from renewables. However, there exist two main disadvantages. First, the investment costs are high compared to conventional heat generation systems like gas boilers. Hereby, it should be noted that air source HP show higher sales figures in comparison to ground source HP (Nowak and Westring (2018)). Thus, the focus within this work lies on air source HP. Second disadvantage is the bad performance during winter - due to low source temperatures - when heat generators must cover the highest space heat demand in buildings. Furthermore, in combination with radiator systems in the existing building stock, these comparatively high sink temperatures amplify the effect of bad performance during times with low outside temperatures.

As a consequence, a composition of an air source heat pump and a condensing gas boiler (CGB), represent- ing one type of hybrid heat generation system, might be an advantageous trade-off between investment cost and seasonal performance. The CGB covers heat demands for domestic hot water (DHW) preparation and critical space heating (SH) requirements. The coverage rate of thermal energy produced by the HP $c r_{\mathrm{HP}, \text { th }}$ compared to the CGB can additionally be increased by self consuming electricity that photo voltaic (PV) cells produce locally.

This paper first presents the calibration of a hybrid system consisting of an air source HP, CGB, combi tank as thermal energy storage (TES) and the system controller. After having gained adequate simulation model, in a second step we perform three scenarios of building performance simulations of one year simulation time each. Hereby, partially a PV system is taken into account. In one scenario the signal of the PV electricity production is utilized by an enhanced energy manager that will take into account the virtually lowered electricity price. In the remaining two scenarios the PV electricity is sold. One of these scenarios does not include a HP but generates heat purely by a CGB. (Steinbach (2018))

\section{Methods}

\section{Measurement Data}

For calibration processes it is necessary to have a comprehensive and dense set of monitoring data. In this case study the data set was gained in a hardwarein-the-loop experiment (Nürenberg et al. (2017)). Hereby, the above mentioned energy conversion system was partially located in a climate chamber and additionally coupled to a hydraulic test bench in order to emulate outdoor air conditions and heat sink, respectively. The latter one means that during the experiment, simulation models of the hydronic network, radiator heat transfer system and building envelope of a single family house were operating and exchanging values with the test benches. Therefore, these highly dynamic tests are called hardware-in-the-loop experiments. Tests with a $1 \mathrm{~s}$ sampling resolution and 4 days with partially heat pump operation phases represent the measurement data base. Figure 1 shows 


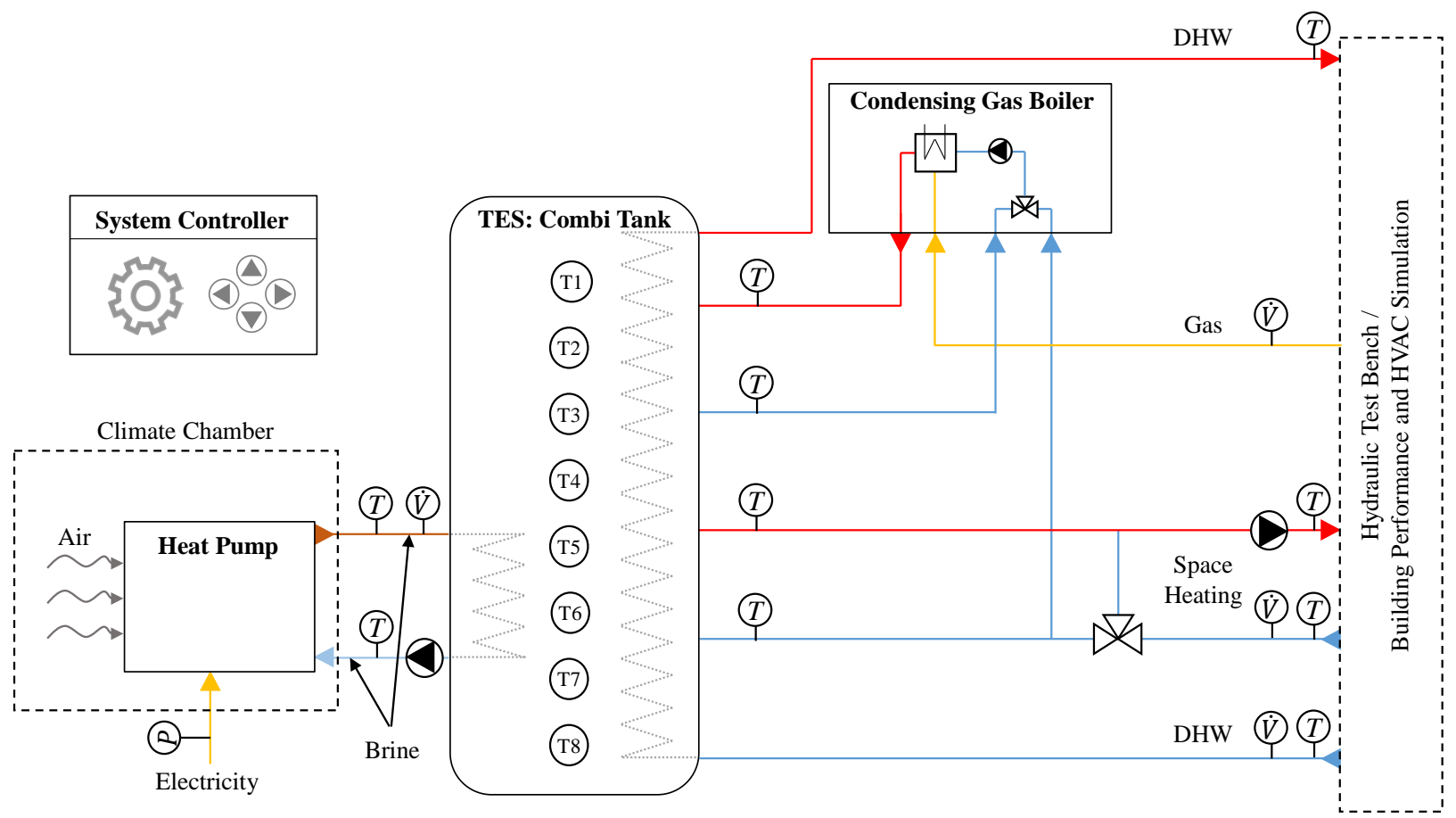

Figure 1: Experimental setup for data acquisition during HiL test (Steinbach (2018)).

the experimental setup and the position of the monitoring equipment. A series of 11 reproducibility tests (Miehlich (2017)) showed uncertainties of measurement regarding provided thermal energy less than $1.85 \%$ and regarding consumed electric energy less than $0.87 \%$.

Unfortunately, since both the CGB and tank are composed to a compact system, there was no possibility to install additional volume flow meters between CGB and tank as well as between the tank's out- and inlets for SH and the unit of pump and three way mixing valve.

The HP is an on/off controlled mono block unit as mono block located in the outdoor surrounding, or in this case located in the climate chamber. The TES is charged via additional piping, where brine is circulating and transporting heat from the HP's condenser to the TES.

\section{Modelling}

Modelica is an open-source and object-oriented modeling language with focus on physical systems (Modelica Association (2018)). Therefore, we model and run building performance and HVAC simulations with Modelica. In the scope of this work we use the freely available model library AixLib (AixLib (2018); Müller et al. (2016)). AixLib is part of the IBPSA Project 1 (IBPSA (2018)) (former IEA EBC Annex 60 (International Energy Agency (2018)). Thus, some models are also part of the core library IBPSA (IBPSA (2018)).

As part of the calibration process, we use the follow- ing HVAC components:

- Heat pump: AixLib.Fluid.

- CGB: HeatPumps. HeatPumpDetailed AixLib.Fluid.BoilerCHP. Boiler

- Combi tank: AixLib.Fluid.Storage. BufferStorage

The HP model bases on tabulated data according to EN 14511 (DIN EN 14511-3 (2018)). Besides this black box approach for the refrigerant circuit, the remaining model parts follow a grey box concept. In particular this means that the model comes along with thermal capacities, heat losses and pressure drops at both heat exchangers condenser (con) and evaporator (eva). The model can be fed by a variable compressor speed signal. However, since the system controller regulates the particular HP under investigation only by an on/off signal, we apply this control strategy to the simulation model as well. The $\mathrm{HP}$ model uses a $\mathrm{PT}_{1}$ element to be able to represent start-up and shut-off phases of the compressor. Furthermore, the heat losses through the condenser to the ambient are characterized by the thermal resistance $R_{\text {HP,loss,con }}$. Additionally, the temperature sensor used in Modelica has a time constant $\tau_{\text {sen,con,out }}$ that represents heat losses to surrounding space. Otherwise, when there is no volume flow, no temperature drop would be simulated for the sensor. Due to compressor limitations, the HP has two safety functions: A minimal operation and lock time after a start-up or shut-off. 
Brine, which is the working fluid in the charging circuit between condenser and TES, has the following fluid properties: specific heat capacity $c_{p}=3.40 \frac{\mathrm{kJK}}{\mathrm{kg}}$ and density $\rho=1.06 \frac{\mathrm{kg}}{\mathrm{l}}$.

Furthermore, besides the above mentioned models for the calibration procedure, the following main components for the system simulations were applied:

- Building envelope:

- Radiator:

AixLib.ThermalZones. HighOrder ....

AixLib.Fluid.HeatExchangers.Radiators.

RadiatorEN442_2

- Valve:

AixLib.Fluid.Actuators. Valves. TwoWayEqualPercentage

- PV:

AixLib.Electrical. PVSystem.PVSystem

- Controller: Modelica models

The radiators and corresponding hydronic network are designed for the temperature triple $(55|45| 20)^{\circ} \mathrm{C}$. The building is a conventional single family house (Constantin et al. (2014)) with a heated net floor area of $146 \mathrm{~m}^{2}$ and a nominal heat load of $7 \mathrm{~kW} \mathrm{~h}$ at $-10^{\circ} \mathrm{C}$ outdoor air temperature.

\section{Control: Basic}

Since we expect the basics of HP and CGB to be known, we give only a short explanation about basic control algorithm of the hybrid system. Typical control approaches are either of economical or ecological nature (Klein et al. (2014)). Whilst for the first one the price ratio of electric energy and gas is the crucial factor, in the latter strategy the ratio of primary energy factors for electricity mix and gas is decisive. All 4 values can be defined in the hybrid system's controller.

The system under investigation has its HP's characteristics saved in the controller logic such that the system is able to predict the operational point for the current combination of outdoor air temperature $T_{\text {oda }}$ and condenser outlet temperature $T_{\text {con,out }}$. Thus, according to (1) and (2) with the predicted power consumptions and efficiencies as well as the given prices for electricity and gas, the system decides for the more cost-effective heat generator. This means, the price ratio is a crucial factor for making the decision which heat generator to switch on at measured outdoor air and demanded sink temperature. For instance, the analyzed system always generates DHW with the CGB.

In other words, the bivalence point becomes dynamic. Besides this economical approach, instead of prices, primary energy factors can be used, which leads to an ecological decision maker. However, this is not part

of the case study this paper presents.

\section{Control: Advanced}

In comparison to the conventional basic control algorithm, an advanced one is implemented as a smarter strategy. Such an advanced controller is able to take a potential current $\mathrm{PV}$ production into account and decide for self consumption instead of selling the generated electricity. It is conceivable to use such a smart controller within a home energy management system. As Wirth (2019) evaluated in Germany from year 2011 onwards self consumption is advantageous over selling the generated PV electricity.

In order to only enable the HP when it is preferable compared to the CGB, heat prices for both energy conversion units are calculated dynamically. Such a heat price quantifies the cost in $€$ for $1 \mathrm{kWh}_{\text {th }}$. Regarding CGB the according heat price $p_{\text {heat,CGB }}$ can easily be calculated according to (1) by dividing the set gas price $p_{\text {gas }}=0.06 € / \mathrm{kWh}$ by the boiler efficiency $\eta_{\mathrm{CGB}}$. In contrast, the HP's heat price $p_{\text {heat,HP }}$ (see (2)) is dependent on the current electric power provided by the PV system $P_{\mathrm{PV} \text {,curr }}$. Furthermore, the algorithm uses the set price signal for the electricity $\mathrm{HP}$ tariff $p_{\mathrm{el}, \text { grid, HP }}=0.21 € / \mathrm{kWh}$ and the revenue received for selling $\mathrm{PV}$ electricity $p_{\mathrm{el}, \mathrm{PV} \text {,sold }}=$ $-0.12 € / \mathrm{kWh}$. All 3 prices were gathered according to price declarations of the local energy supplier. The $\max \{\}$ function in (2) limits the predicted heat price $p_{\text {heat,HP }}$ to 0 in case of $P_{\mathrm{PV}, \text { curr }}>P_{\mathrm{el}, \mathrm{HP} \text {,pred }}$.

$$
\begin{aligned}
p_{\text {heat }, \mathrm{CGB}} & =\frac{p_{\text {gas }}}{\eta_{\mathrm{CGB}}} \\
p_{\text {heat }, \mathrm{HP}} & =\max \left\{p_{\text {el,grid,HP }} \frac{P_{\text {el,HP,pred }}-P_{\mathrm{PV}, \text { curr }}}{P_{\text {el }, \mathrm{HP}, \text { pred }} \cdot \mathrm{COP}_{\text {pred }}}, 0\right\}
\end{aligned}
$$

To reduce (2) to the baseline scenario and its control algorithm, $P_{\mathrm{PV} \text {,curr }}$ can be set to 0 .

\section{Calibration}

In order to calibrate the whole energy system adequately, it is not treated as one model but as 4 individual grey box models. Figure 2 displays the decomposition of the whole system for calibration purposes.

Figure 2 shows the applied calibration process. Within the context of this work, we relied on a mostly manual calibration procedure by applying expert knowledge rather than using an automated process.

The calibration was performed using the Design library (Elmqvist et al. (2005)), which comes along with the simulation environment Dymola (Dassault Systèmes (2018)).

For the subsystem controller we identified the temperatures and sensor positions in the combi tank that represent the hystereses' boundaries for enabling and disabling DHW or SH mode. In contrast, for the sub- 


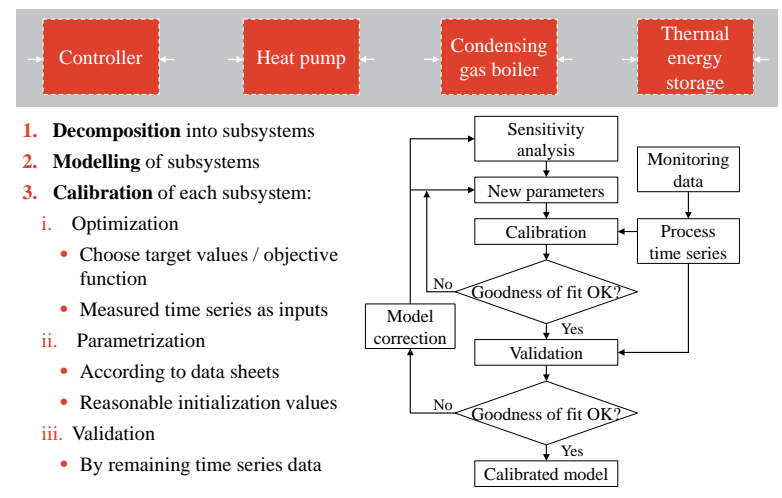

Figure 2: Idea and procedure of calibrating the complex energy conversion system (Steinbach (2018)).

systems heat pump, condensing gas boiler and thermal energy storage, we carefully chose parameters that are tuned in order to minimize the objective function. The objective functions are the root-meanquare errors (RMSE) of measured and simulated target values. Besides this, also certain measured values at the boundary of the decomposed control volume must be defined as input variables for the simulation model. All these information are listed in tables in section "Results Calibration".

In order to achieve a good calibrated system model, adequate operational classes for each subsystem must be defined. Therefore, we determined the following classes sorted to their subsystem:

1. Controller

(a) DHW on/off hysteresis

(b) $\mathrm{SH}$ on/off hysteresis

2. Heat pump

(a) Operation mode

(b) Disabled mode

3. Condensing gas boiler

(a) Operation mode

4. Thermal energy storage

(a) Stand-by (no charging or discharging)

(b) Charging via heat pump circuit

(c) DHW tapping

Within the use case two issues are worth to mention: First, the controller is not easy to calibrate, since every manufacturer wants to protect their intellectual property. Thus, the mostly rule based decision statements must be gathered from data sheets and eventually some re-engineering. Therefore, in section "Results Calibration" we explain how we identified the hystereses' trigger values. This issue is a general problem that is hard to handle within the context of calibrations of complex energy conversion systems.
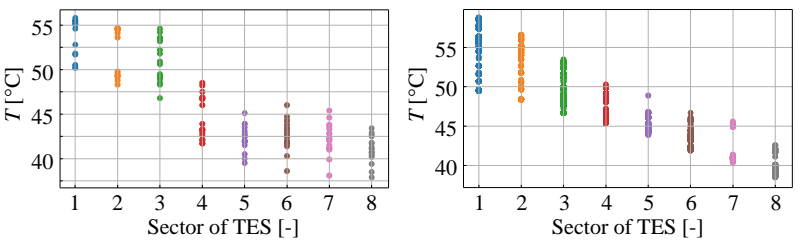

Figure 3: TES temperatures before and after switchings modes: DHW (left) and $\mathrm{SH}$

(right) (Steinbach (2018)).

Second, due to too little space between CGB and TES, we were not able to install any volume flow meter. As a conclusion, no energy balancing for the boiler's control volume is possible. Therefore, no class for charging TES with CGB exists. Analogously, we could not create a class for discharging the TES in $\mathrm{SH}$ mode.

\section{Results Calibration}

\section{Controller}

As written above, we implemented the controller algorithm mostly according to given expert manuals. Additionally, we identified the hystereses' trigger temperatures suiting to our installed sensors. Since we model the TES with 8 discretized layers, analogously to our attached 8 temperature sensors (see Figure 1), we use these temperature information for the controller model.

Figure 3 shows the monitoring data for each point assigned to the belonging sensor number.

From a qualitative investigation, we identify layer 2 and layer 7 as temperature layers that can be used as controller input for DHW and SH mode, respectively. The standard deviations for these layers show the highest value, which is not a proof but at least it indicates each an upper and lower hysteresis boundary. We identified in layer 2 a temperature of $54^{\circ} \mathrm{C}$ as upper and $49^{\circ} \mathrm{C}$ as lower boundary of the DHW hysteresis. Analogously, in layer 7 the temperatures are $45^{\circ} \mathrm{C}$ and $40^{\circ} \mathrm{C}$ that represent upper and lower boundary, respectively, of the $\mathrm{SH}$ hysteresis. Actually, this can be interpreted and transferred as a $5 \mathrm{~K}$ spread around the target supply temperature set by the heating curve.

\section{Heat Pump}

The following tables give a clear overview of each calibration class. The Nomenclature section at the end of the paper denotes all variable names. We performed the calibration process with tuner parameter values that are restricted between a low and a high boundary. The calibration process begins with the start values given in the tables. Additionally, the final selection for each tuner parameter is displayed. 
For each simulated time span we chose reasonable initialization values where necessary, e.g. start temperature for the TES' layers in the model. This is an essential issue that must be taken into account when calibrating complex energy systems with large thermal masses.

Table 1: Calibration overview for component and

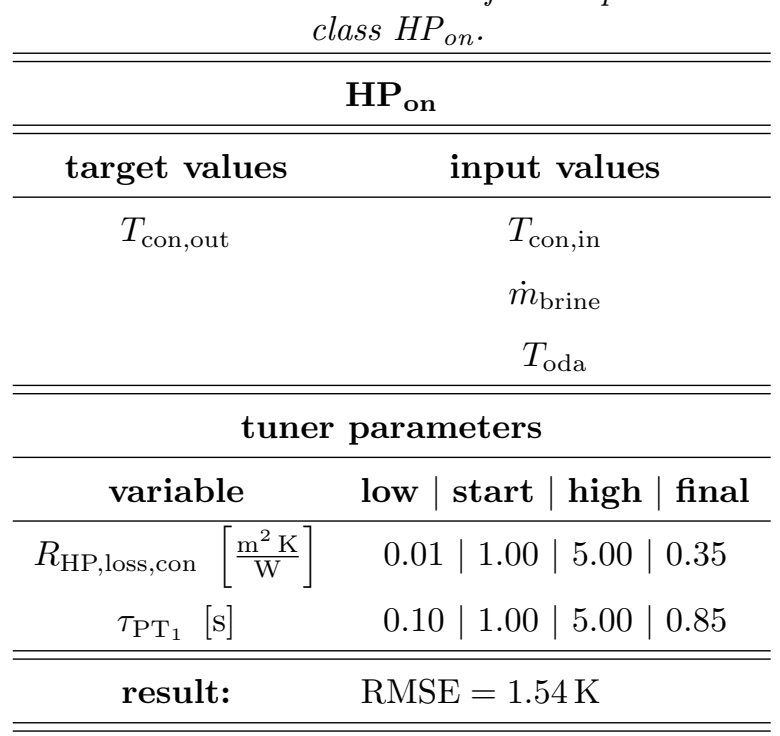

Table 2: Calibration overview for component and

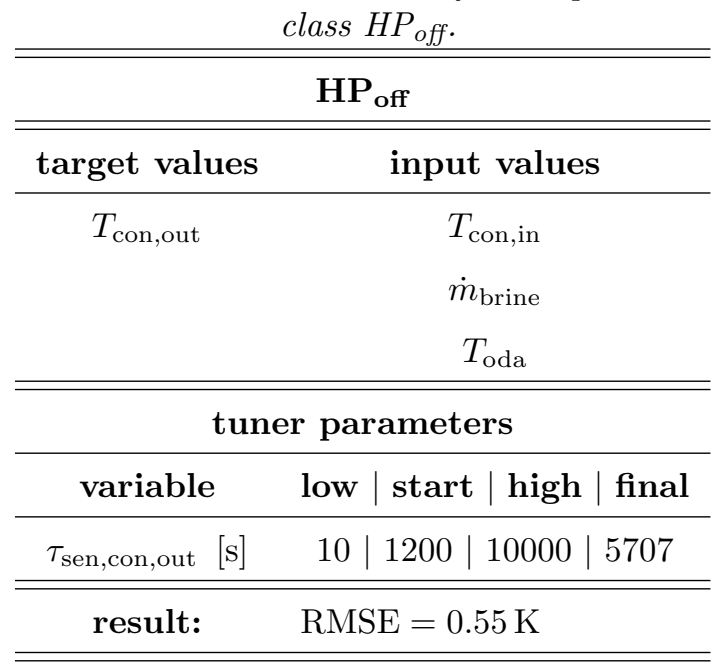

Figure 4 visualizes for an appropriate time phase the validation results for both $\mathrm{HP}_{\text {on }}$ and $\mathrm{HP}_{\text {off }}$ class. The curves show good congruence, which also expresses the total RMSE $=1.02 \mathrm{~K}$ as combination of both HP classes.

We implemented a delay for switching off the brine's circulation pump after the HP's compressor stops. Thus, analogously to the experiment observations, the system transports some heat out of the condenser still after switching the HP unit off.

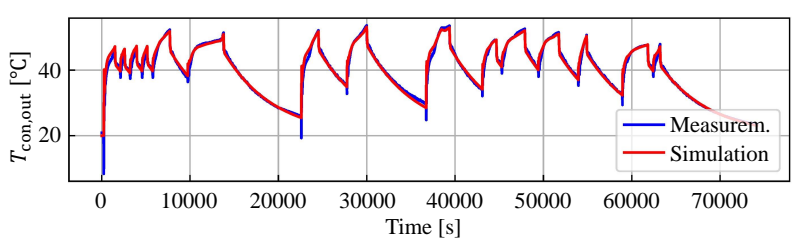

Fiaure 4: Validation results of HP calibration.

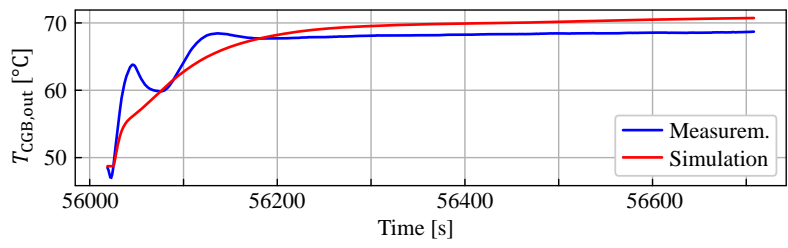

Figure 5: Validation results of $C G B$ calibration.

\section{Condensing Gas Boiler}

The second heat generator, the CGB, is calibrated only for its operation times. However, we validated this class with three extracted time spans (ts) from the experiment. The calibration summary displays Table 3.

Table 3: Calibration overview for component and class $C G B$.

\begin{tabular}{cc}
\hline \hline \multicolumn{2}{c}{ CGB } \\
\hline \hline target values & input values \\
\hline$T_{\mathrm{CGB}, \text { out }}$ & $T_{\mathrm{CGB}, \mathrm{in}}$ \\
\hline \hline \multicolumn{2}{c}{ tuner parameters } \\
\hline variable & low $\mid$ start $\mid$ high $\mid$ final \\
\hline$\dot{m}_{\mathrm{CGB}}\left[\frac{\mathrm{kg}}{\mathrm{s}}\right]$ & $0.100|0.200| 0.300 \mid 0.216$ \\
\hline \hline result: & $\mathrm{RMSE}_{\mathrm{ts} 1}=1.43 \mathrm{~K}$ \\
& $\mathrm{RMSE}_{\mathrm{ts} 2}=1.89 \mathrm{~K}$ \\
& $\mathrm{RMSE}_{\mathrm{ts} 3}=1.77 \mathrm{~K}$ \\
\hline \hline
\end{tabular}

As one can see from the validation visualization of one time span in Figure 5, especially during the start-up phase, the measured and simulated CGB outlet temperature $T_{\mathrm{CGB} \text {,out }}$ deviate significantly. Furthermore, the following quasi-stationary operation shows a minor offset. The unconventional measured heat up behavior is probably due to little water masses that are in the system's piping between tank and CGB. These volumes have lower and higher temperatures since the $\mathrm{CGB}$ can receive water from the $\mathrm{DHW}$ or $\mathrm{SH}$ sector of the tank (compare Figure 1). 


\section{Thermal Energy Storage}

As mentioned above, we divided the calibration of the TES into three classes. Overviews can be found in Table 4 - 6 . In all classes the layer temperatures $T_{\mathrm{TES}}$ represent the target values. Since the heating coil for tank charging via HP is located in the lower section of the TES, only layers $5-8$ are from greater interest for

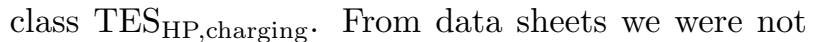
able to extract exact material properties. Thus, especially conductive $(\lambda)$ and convective $(h)$ heat transfer coefficients predestined to be the tuner parameters for the calibration process. Furthermore, the surrounding outside (outs) temperature in the test hall, where the tank was located during the experiment, was not exactly known. Thus, $T_{\text {outs }}$ is also a free parameter.

Table 4: Calibration overview for component and class TES $S_{\text {stand-by. }}$

\begin{tabular}{cc}
\hline \hline & TES \\
\hline \hline target values & input values \\
\hline$T_{\mathrm{TES}, 1-8}$ & \\
\hline \hline & tuner parameters \\
\hline variable & low $\mid$ start $\mid$ high $\mid$ final \\
\hline$h_{\text {outs }}\left[\frac{\mathrm{W}}{\mathrm{m}^{2} \mathrm{~K}}\right]$ & $5|10| 15 \mid 10$ \\
$h_{\text {insi }}\left[\frac{\mathrm{W}}{\mathrm{m}^{2} \mathrm{~K}}\right]$ & $80|100| 120 \mid 100$ \\
$\lambda_{\text {wall }}\left[\frac{\mathrm{W}}{\mathrm{mK}}\right]$ & $25|50| 75 \mid 50$ \\
$\lambda_{\text {insu }}\left[\frac{\mathrm{W}}{\mathrm{mK}}\right]$ & $0.025|0.043| 0.075 \mid 0.075$ \\
$T_{\text {outs }}\left[{ }^{\circ} \mathrm{C}\right]$ & $15|20| 25 \mid 15$ \\
\hline \hline result: & $\mathrm{RMSE}=0.29 \mathrm{~K}$ \\
\hline \hline
\end{tabular}

Inside the tank, the two heat exchanger helixes do not form a perfectly equidistant spiral from their inlets to their according outlets. Furthermore, the heat exchangers exist of corrugated pipes. This results in a not known heat transmitting length and surface. As a conclusion, we chose the lengths $l_{\text {coil }}$ for DHW and intermediate brine circuit between HP and tank to be tuneable. Similar to the thermal properties at the tank's wall, the convective heat transfer coefficients $h_{\text {coil }}$ between outer pipe surface and tank's water volume are variable between reasonable boundaries.

For class TES $_{\mathrm{HP} \text {,charging }}$ besides selected layer temperatures, the brine temperature $T_{\text {con,in }}$ coming out of the TES heat exchanger and flowing into the HP's condenser represents a target value. Unfortunately, the RMSE $\left(T_{\text {con,in }}\right)=3.26 \mathrm{~K}$ does not show a satisfying result. In contrast, in all three TES classes we achieved a good RMSE $\left(T_{\mathrm{TES}}\right)$.
Table 5: Calibration overview for component and class TES $S_{H P, \text { charging. }}$

\begin{tabular}{|c|c|}
\hline \multicolumn{2}{|c|}{ TES $_{\text {HP,charging }}$} \\
\hline target values & input values \\
\hline$T_{\text {con,in }}$ & $T_{\text {con,out }}$ \\
\hline$T_{\mathrm{TES}, 5-8}$ & $\dot{m}_{\text {brine }}$ \\
\hline \multicolumn{2}{|c|}{ tuner parameters } \\
\hline variable & low | start | high | final \\
\hline$l_{\text {coil }, \mathrm{HP}}[\mathrm{m}]$ & $9.43|18.85| 28.28 \mid 28.28$ \\
\hline$h_{\text {coil }, \mathrm{HP}}\left[\frac{\mathrm{W}}{\mathrm{m}^{2} \mathrm{~K}}\right]$ & $50.00|100.00| 150.00 \mid 65.63$ \\
\hline \multirow[t]{2}{*}{ result: } & $\operatorname{RMSE}\left(T_{\text {con,in }}\right)=3.26 \mathrm{~K}$ \\
\hline & $\operatorname{RMSE}\left(T_{\mathrm{TES}, 5-8}\right)=0.57 \mathrm{~K}$ \\
\hline
\end{tabular}

Table 6: Calibration overview for component and class $T E S_{D H W, \text { tapping. }}$

\begin{tabular}{|c|c|c|c|c|}
\hline \multicolumn{5}{|c|}{ TES $_{\text {DHW,tapping }}$} \\
\hline \multicolumn{2}{|c|}{ target values } & & input values & \\
\hline \multirow{2}{*}{\multicolumn{2}{|c|}{$T_{\mathrm{TES}, 1-8}$}} & & $T_{\mathrm{DHW}, \text { cold }}$ & \\
\hline & & & $\dot{m}_{\mathrm{DHW}}$ & \\
\hline \multicolumn{5}{|c|}{ tuner parameters } \\
\hline \multicolumn{2}{|c|}{ variable } & low & start | high | & final \\
\hline \multicolumn{2}{|c|}{$l_{\text {coil,DHW }}[\mathrm{m}]$} & 5.85 & $11.70|17.55|$ & 17.55 \\
\hline$h_{\text {coil,DHW }}$ & $\left.\frac{\mathrm{W}}{\mathrm{m}^{2} \mathrm{~K}}\right]$ & 50.00 & $100.00 \mid 150.00$ & | 50.18 \\
\hline \multicolumn{2}{|c|}{ result: } & RMSE & $=0.60 \mathrm{~K}$ & \\
\hline
\end{tabular}

\section{Results System Simulations}

Within the scope of the system simulations, we simulated and analyzed three different scenarios:

- Scen. 1: CGB, no HP, no PV self consumption

- Scen. 2: CGB, HP, no PV self consumption

- Scen. 3: CGB, HP, PV self consumption

In cases of no PV self consumption all electricity produced by the PV cells is sold (fed to the grid). In contrast, Scen. 3 uses the advanced controller (see section "Control: Advanced") which uses current PV signal to enable the HP and raise the HP's thermal coverage rate $c r_{\mathrm{HP}, \mathrm{th}}$ of the whole hybrid system (compare (2)). The remaining electricity, when $P_{\mathrm{PV} \text {,curr }}-P_{\mathrm{el}, \mathrm{HP} \text {, actual }}>0 \mathrm{~W}$, is also sold to the grid like in the other scenarios.

Table 7 expresses the results from an economical point of view.

The advanced controlled Scen. 3 results in more oper- 
Table 7: Main results of system simulations.

\begin{tabular}{lccc}
\hline & Scen. 1 & Scen. 2 & Scen. 3 \\
\hline $\operatorname{cr}_{\mathrm{HP}, \text { th }}[\%]$ & 0 & 13 & 16 \\
$c_{\text {oper }}[€ / \mathrm{a}]$ & 684 & 758 & 768 \\
\hline \hline
\end{tabular}

ational time of the HP. Thus, a positive effect is that the HP coverage rate can be increased from $13 \%$ to $16 \%$. As a consequence, this advanced control strategy also raises the consumption of renewable energy. From an economical point of view the pure CGB scenario shows the lowest operational expenses. Additionally, this system would have much lower investment costs. An evaluation of the resulting indoor temperatures does not show worse user comfort in Scen. 1 compared to the other ones. This means the CGB as single heat generator is able to cover the heat demand in a satisfying way from occupants' point of view. Furthermore, the smart controlled Scen. 3 results in even slightly higher operational cost in comparison to Scen. 2, where no PV electricity is self consumed but all of it is sold.

In the following paragraph we explain the issue, why the HP scenarios are less good compared to the CGB system. Within the context of the system simulations we recognized that the condenser outlet temperatures rises relatively fast. This observation was also experienced in the Hardware-in-the-loop experiments. Mostly, after some time of HP operation, the condenser outlet temperature was above the supply temperature, which is set by the heating curve settings. As a consequence, the actual momentary COP becomes worse than the predicted COP. And thus, the operation of HP instead of CGB turns into a non-economical operation. The marked areas in Figure 6 visualize the condenser outlet temperature at the beginning below the set temperature and after a crossing point above the set value coming from the heating curve or DHW target temperature. As long as the brine mass flow through the condenser is not regulated - and in this experimental setup we only measured constant mass flow - and the HP is on/off controlled, actually it is not possible to achieve exactly the target temperature. Thus, the expected COP is normally not met, which of course leads the economical decision maker on the wrong track. Additionally, a HP always has start-up and shut-off losses and does not directly operate in a steady-state mode, in which the efficiency values from the data sheet are gained.

The bottom line is that with an adaption of the controller strategy, which takes not only the momentary heat price into account but also the dynamic development of the COP according to rising condenser outlet temperatures, could solve the issue.

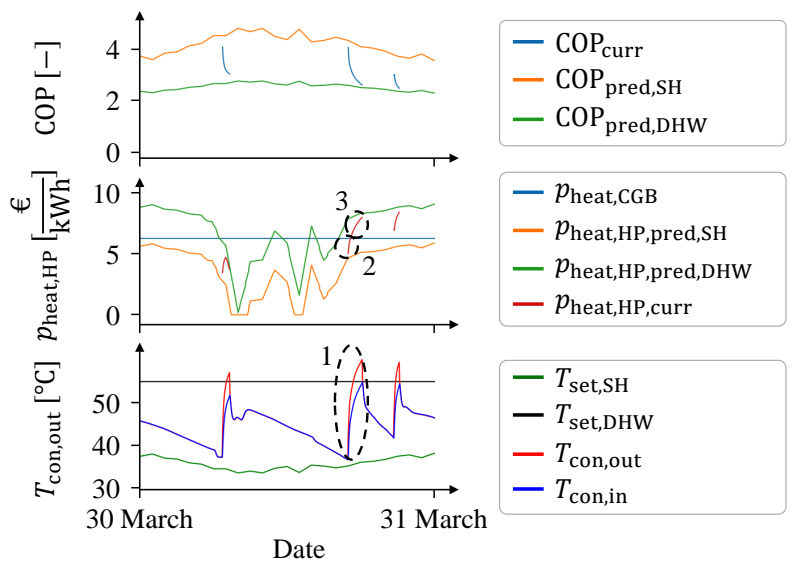

Figure 6: Issues that COP and heat price $p_{\text {heat }}$ is dynamic and becoming worth than predicted. Data with index "curr" only plotted, when HP is

operating. 1: $T_{\text {con,out }}$ rises, which leads to a bad actual $C O P_{\text {curr }}$. 2: Due to low temperature $T_{\text {con,out }}$

$H P$ heat price is is lower than CGB's one. 3: Intersection - CGB operation would be preferable but due to minimal HP operation time, HP cannot be turned off.

\section{Conclusion}

\section{Calibration Procedure}

Within the context of calibrating HVAC systems the paper follows the approach of decomposing the complex energy conversion system into wisely chosen subsystems - in this case study these are system controller, heat pump, condensing gas boiler and thermal energy storage. With expert knowledge we selected calibration classes and tuner parameters that led to a satisfying calibration result in terms of RMSE. However, a more automated calibration procedure is desirable, for each subsystem different advices should be followed and predefined, which this paper is a good basis for.

\section{System Simulations}

The simulated scenarios present that an energy supply system, purely consisting of a condensing gas boiler, lead to lowest yearly operational costs in comparison to a hybrid heat pump system. This is due to neglecting dynamic effects such as losses during start-up and shut-off phases or heat losses in the components, especially the thermal energy storage, and relying on ideal COP from the characteristic field. Additionally, an on/off controlled heat pump with a constant mass flow rate on condenser's secondary side is not able to always meet the target supply temperature, even in steady state mode. Thus, the pure quasi-stationary COP of the heat pump's characteristic field are not a sufficient measure to decide for a heat generator. However, the advanced control strategy to maximize self consumption considering photovoltaic electricity generation is able to slightly raise 
the heat pump coverage rate.

\section{Nomenclature}

- $c_{\text {oper }}=$ operational costs

- $c_{p}=$ specific heat capacity

- $c r_{\mathrm{HP}, \mathrm{th}}=$ thermal heat pump coverage rate

- $\mathrm{CGB}=$ condensing gas boiler

- $\operatorname{con}=$ condenser

- $\mathrm{COP}=$ coefficient of performance

- $\quad$ curr = current

- $\mathrm{DHW}=$ domestic hot water

- el = electric / electrical

- $\eta=$ efficiency

- eva = evaporator

- $h=$ convective heat transfer coefficient

- $\mathrm{HP}=$ heat pump

- $\mathrm{HVAC}=$ heating, ventilation and air conditioning

- IBPSA = international building performance simulation association

- in = inlet

- insi = inside

- insu = insulation

- $\lambda=$ conductive heat transfer coefficient

- oda = outdoor air

- out = outlet

- outs $=$ outside

- $p=$ price

- $P=$ electric power

- pred = predicted

- $\mathrm{PV}=$ photovoltaic

- $\rho=$ fluid density

- $R=$ thermal resistance

- $\mathrm{RMSE}=$ root-mean-square error

- $\operatorname{sen}=$ sensor

- $\mathrm{SH}=$ space heating

- $\tau=$ time constant

- $T=$ temperature

- $\mathrm{TES}=$ thermal energy storage

- $\mathrm{ts}=$ time span

- $\dot{V}=$ volume flow

\section{References}

AixLib (2018). Aixlib - a modelica model library for building performance simulations. https:// github.com/RWTH-EBC/AixLib.

Constantin, A., R. Streblow, and D. Müller (2014). The modelica housemodels library: Presentation and evaluation of a room model with the ashrae standard 140. In The 10th International Modelica Conference, Linköping Electronic Conference Proceedings, pp. 293-299. Linköping University Electronic Press.
Dassault Systèmes (2018). Dymola. https: //www.3ds.com/de/produkte-und-services/ catia/produkte/dymola/.

DIN EN 14511-3 (2018). Air conditioners, liquid chilling packages and heat pumps for space heating and cooling and process chillers, with electrically driven compressors - Part 3: Test methods; EN 14511$3: 2018$.

Elmqvist, H., H. Olsson, S. E. Mattsson, D. Brück, C. Schweiger, D. Joos, and M. Otter (2005). Optimization for design and parameter estimation. In Proc. of 4 th International Modelica Conference, pp. 255-266.

IBPSA (2018). Ibpsa project 1: Bim/gis and modelica framework for building and community energy system design and operation. https:// ibpsa.github.io/project1/. [Online; accessed 29-January-2019].

International Energy Agency (2018). Iea ebc annex 60: New generation computational tools for building and community energy systems based on the modelica and functional mockup interface standards. http://www.iea-annex60.org/. [Online; accessed 29-January-2019].

Klein, K., K. Huchtemann, and D. Müller (2014). Numerical study on hybrid heat pump systems in existing buildings. Energy and Buildings 69, 193-201.

Miehlich, A. (11 / 2017). Studies on the repeatability of Hardware-in-the-loop experiments. Master's thesis (original language: German), RWTH Aachen University, Aachen.

Modelica Association (2018). Modelica. https: //www.modelica.org/. [Online; accessed 29January-2019].

Müller, D., M. Lauster, A. Constantin, M. Fuchs, and P. Remmen (2016). Aixlib - an open-source library within the iea-ebc annex60 framework. In BauSIM 2016: Sixth German-Austrian IBPSA Conference, pp. 3-9.

Nowak, T. and P. Westring (2018). European heat pump market and statistics report 2018.

Nürenberg, M., P. Mehrfeld, K. Huchtemann, and D. Müller (2017). Hardware-in-the-loop test bench setup and its application to determine seasonal performance of heat pump systems.

Steinbach, M. (07 / 2018). Creation and analysis of building performance simulations with focus on calibrated models of heat pump systems. Master's thesis (original language: German), RWTH Aachen University, Aachen.

Wirth, H. (2019). Aktuelle fakten zur photovoltaik in deutschland. 